\title{
Antibiotic stewardship teams and Clostridioides difficile practices in United States hospitals: A national survey in The Joint Commission antibiotic stewardship standard era
}

\author{
Valerie M. Vaughn MD, MSc ${ }^{1,2,3}$, M. Todd Greene PhD, $\mathrm{MPH}^{1,2,3}$, David Ratz $\mathrm{MS}^{1,3}$, Karen E. Fowler $\mathrm{MPH}^{1,3}$, \\ Sarah L. Krein PhD, RN ${ }^{1,2,3}$, Scott A. Flanders $M D^{2,3}$, Erik R. Dubberke $M^{4}$, Sanjay Saint MD, MPH ${ }^{1,2,3}$ and \\ Payal K. Patel MD, MPH $5,2,3$ \\ ${ }^{1}$ Center for Clinical Management Research, Veterans Affairs (VA) Ann Arbor Healthcare System, Ann Arbor, Michigan, ${ }^{2}$ Department of Internal Medicine, \\ University of Michigan (UM) Medical School, Ann Arbor, Michigan, ${ }^{3}$ VA/UM Patient Safety Enhancement Program, Ann Arbor, Michigan, ${ }^{4}$ Department of Internal \\ Medicine-Infectious Disease, Washington University School of Medicine, St Louis, Missouri and ${ }^{5}$ Division of Infectious Diseases, VA Ann Arbor Healthcare System, \\ Ann Arbor, Michigan
}

\begin{abstract}
Objective: Clostridioides difficile infection (CDI) can be prevented through infection prevention practices and antibiotic stewardship. Diagnostic stewardship (ie, strategies to improve use of microbiological testing) can also improve antibiotic use. However, little is known about the use of such practices in US hospitals, especially after multidisciplinary stewardship programs became a requirement for US hospital accreditation in 2017. Thus, we surveyed US hospitals to assess antibiotic stewardship program composition, practices related to CDI, and diagnostic stewardship.

Methods: Surveys were mailed to infection preventionists at 900 randomly sampled US hospitals between May and October 2017. Hospitals were surveyed on antibiotic stewardship programs; CDI prevention, treatment, and testing practices; and diagnostic stewardship strategies. Responses were compared by hospital bed size using weighted logistic regression.

Results: Overall, 528 surveys were completed (59\% response rate). Almost all (95\%) responding hospitals had an antibiotic stewardship program. Smaller hospitals were less likely to have stewardship team members with infectious diseases (ID) training, and only $41 \%$ of hospitals met The Joint Commission accreditation standards for multidisciplinary teams. Guideline-recommended CDI prevention practices were common. Smaller hospitals were less likely to use high-tech disinfection devices, fecal microbiota transplantation, or diagnostic stewardship strategies.

Conclusions: Following changes in accreditation standards, nearly all US hospitals now have an antibiotic stewardship program. However, many hospitals, especially smaller hospitals, appear to struggle with access to ID expertise and with deploying diagnostic stewardship strategies. CDI prevention could be enhanced through diagnostic stewardship and by emphasizing the role of non-ID-trained pharmacists and clinicians in antibiotic stewardship.
\end{abstract}

(Received 2 August 2019; accepted 14 October 2019; electronically published 6 December 2019)

Unnecessary and inappropriate antibiotic use leads to antibiotic resistance and one of the most common and deadly healthcareassociated infections: Clostridioides difficile infection (CDI). ${ }^{1,2}$ Clostridioides difficile accounts for nearly half a million infections and 15,000 deaths annually in the United States (US) alone. ${ }^{3}$ The US government has used a combination of financial incentives, public reporting, and regulatory oversight to try to reduce healthcare-associated infections. Although these policies have

Author for correspondence: Valerie M. Vaughn, Email: valmv@umich.edu

Cite this article: Vaughn VM, et al. (2020). Antibiotic stewardship teams and Clostridioides difficile practices in United States hospitals: A national survey in The Joint Commission antibiotic stewardship standard era. Infection Control \& Hospital Epidemiology, 41: 143-148, https://doi.org/10.1017/ice.2019.313 led to decreases in most healthcare-associated infections, CDI and deaths from CDI have not decreased. ${ }^{4,5}$

Successful strategies for reducing CDI include antibiotic stewardship and infection prevention. ${ }^{6}$ For example, England implemented a national CDI prevention campaign in 2007 emphasizing both antibiotic stewardship and infection prevention. That program reduced CDI and related mortality by at least $60 \%{ }^{7}$ Although the US has adopted many infection prevention measures, it has been slower to adopt antibiotic stewardship. In a 2013 national survey, we found that although infection prevention practices for CDI were nearly universal in US hospitals, only $52 \%$ had an antibiotic stewardship program. ${ }^{8}$ The same year, an analysis of the National Healthcare Safety Network Annual Hospital Survey found that only 39\% of US hospitals met all of the Centers for Disease Control and

(C) The Society for Healthcare Epidemiology of America 2019. All rights reserved. This is an Open Access article, distributed under the terms of the Creative Commons Attribution licence (http://creativecommons.org/licenses/by/4.0/), which permits unrestricted reuse, distribution, and reproduction in any medium, provided the original work is properly cited. 
Prevention (CDC) "core elements" for antibiotic stewardship programs. ${ }^{9}$ This deficit in antibiotic stewardship is concerning given mounting data suggesting that antibiotic stewardship plays a larger role than infection prevention in reducing CDI. ${ }^{10}$

To address the continued problem of antibiotic overuse and CDI, the major hospital accrediting body in the US, The Joint Commission, made antibiotic stewardship programs a condition for hospital accreditation as of January 1, 2017. Specifically, The Joint Commission began requiring hospitals to have multidisciplinary stewardship teams including the following, when available: (1) an infectious diseases (ID) physician, (2) an infection preventionist, (3) a pharmacist, and (4) a practitioner (not defined; presumed in this analysis to include any physician). ${ }^{11}$ Concurrently, the US is facing a shortage of available ID specialists, especially those with antibiotic stewardship expertise. ${ }^{12}$ Whether all US hospitals, especially smaller hospitals that may have limited resources and staffing, have been able to meet The Joint Commission goal is not known. This concern led the CDC to recommend that critical access hospitals ( $<25$ beds) include a pharmacist and a "physician leader" on their stewardship team. ${ }^{13}$

Furthermore, since our 2013 survey, the concept of "diagnostic stewardship" - or strategies and policies to improve appropriate use of microbiological testing - has expanded as a key method to improve antibiotic use. ${ }^{14}$ Similarly, the adoption of many methods to prevent, treat, and improve testing for CDI, has not been well characterized. In 2017, we conducted a random survey of US hospitals to determine the following: (1) the presence and composition of antibiotic stewardship programs; (2) current methods of CDI prevention, treatment, and testing; (3) diagnostic stewardship practices; and (4) whether antibiotic stewardship program composition, CDI prevention strategies, and diagnostic stewardship vary by hospital bed size.

\section{Methods}

\section{Data collection}

The current study was part of an ongoing survey in which, every 4 years, we ask infection preventionists across the US what practices their hospitals are using to prevent common healthcare-associated infections. ${ }^{8,15-17}$ Survey methods have been previously described. ${ }^{16}$ Briefly, we randomly sampled 900 medical and surgical hospitals with an intensive care unit across the US. Three hospitals were excluded from the study due to closure or status change. Surveys were mailed in May 2017, with subsequent reminders to nonresponders. Hospitals that employed $>1$ infection preventionist were asked to have the lead infection preventionist serve as the primary respondent, though we encouraged consulting with others to complete the questionnaire. Hospital characteristics, including bed size and The Joint Commission accreditation status, were obtained by linking to the 2013 American Hospital Association database. Institutional review board approval as an exempt study was obtained from the University of Michigan.

\section{Survey measures}

Similar to prior surveys, ${ }^{15-17}$ participants were queried regarding hospital characteristics and details of their infection prevention programs. In addition, participants were asked how frequently certain CDI prevention practices were used in their facility (responses: 1 [never] to 5 [always]). ${ }^{8}$ We defined responses of 4 or 5 (ie, "almost always" or "always") as regular use of the respective CDI prevention practices. Hospitals were also asked, "Has your hospital implemented a urine culture stewardship initiative? (Yes/No)" and "Does your hospital have an antibiotic stewardship program? (Yes/No).” If participants answered yes to having an antibiotic stewardship program, they were asked to indicate who of the following was on their antibiotic stewardship team: (1) infection preventionist, (2) ID physician, (3) hospitalist (primarily inpatient general internist), (4) other physician, (5) pharmacist (with ID training), (6) pharmacist (without ID training), (7) nurse, or (8) other.

\section{Data analysis}

To create nationally representative estimates, survey responses are shown as weighted proportions, with sampling weights based on the inverse probability of selection and response by bed size. To evaluate whether antibiotic stewardship program composition and CDI strategies varied by bed size, we used weighted logistic regression with hospital bed size as a continuous variable. Odds ratios are reported for every 10 -bed increase. For ease of visualization, responses were separated into 3 commonly used bed-size categories: $<50$ beds (small), 50-250 beds (medium), $>250$ beds (large). $P<.05$ was considered statistically significant. We used SAS version 9.4 software (SAS Institute, Cary, NC) for all analyses.

\section{Role of the funding source}

The funders of the study had no role in the study design; data collection, analysis, or interpretation; writing of the report; or in the decision to submit the paper for publication. The corresponding author had full access to all study data and had final responsibility for the decision to submit for publication.

\section{Results}

The survey response rate was 59\% (530 of 897). Two responding hospitals $(0.2 \%)$ could not be linked to bed size data and were excluded, leaving 528 hospitals in the final analysis. Hospital characteristics are shown in Table 1.

\section{Antibiotic stewardship team composition}

Nearly all (95\%) hospitals reported having an antibiotic stewardship program. Most stewardship teams had a pharmacist (99\%), a physician (95\%, including ID physician [69\%], hospitalist [48\%], or other physician [44\%]), and/or an infection preventionist (91\%). Team members with ID training were less common: $52 \%$ of antibiotic stewardship programs had an ID-trained pharmacist, and $69 \%$ had an ID physician. Although most hospitals (78\%) had either an ID physician or ID pharmacist, only $43 \%$ had both. Less than half of hospitals (41\%) met The Joint Commission accreditation standard (ID physician, infection preventionist, pharmacist, practitioner); however, most hospitals (95\%) met the minimum standards set by the CDC for critical access hospitals (pharmacist, physician).

As bed size increased, hospitals were more likely to have antibiotic stewardship team members (eg, hospitalists, non-ID physicians, nurses) with ID training (Fig. 1). In contrast, the presence of generalists on antibiotic stewardship team did not vary by bed size. Larger hospitals were more likely to meet both The Joint Commission recommendation for multidisciplinary stewardship programs and the CDC minimum recommendations for criticalaccess hospitals (Table 2). 
Table 1. Hospital Characteristics

\begin{tabular}{|c|c|}
\hline Variable & No. \\
\hline Acute care beds, mean $(95 \% \mathrm{Cl})$ & $216(199-234)$ \\
\hline Intensive care beds, mean $(95 \% \mathrm{Cl})$ & $16(14-17)$ \\
\hline Affiliated with a medical school, $\%(95 \% \mathrm{CI})^{a}$ & $26(22-30)$ \\
\hline Have a hospital epidemiologist, \% $(95 \% \mathrm{CI})^{\mathrm{a}}$ & $41(37-46)$ \\
\hline $\begin{array}{l}\text { Full-time equivalents for infection preventionists, } \\
\text { mean }(95 \% \mathrm{CI})^{\mathrm{a}}\end{array}$ & $1.8(1.6-2.1)$ \\
\hline Have hospitalist physicians, $\%(95 \% \mathrm{Cl})$ & $84(80-87)$ \\
\hline \multicolumn{2}{|l|}{ Hospital payer, \% (95\% CI) } \\
\hline Not-for-profit & $73(69-77)$ \\
\hline Government (nonfederal) & $16(13-19)$ \\
\hline For-profit & $11(9-14)$ \\
\hline \multicolumn{2}{|l|}{ Geographic region, \% (95\% CI) } \\
\hline South & $33(29-37)$ \\
\hline Northeast & $18(15-21)$ \\
\hline Midwest & $30(26-34)$ \\
\hline West & $18(15-21)$ \\
\hline Other & $1(0.2-2)$ \\
\hline Accredited by The Joint Commission, \% (95\% CI) & $75(71-79)$ \\
\hline
\end{tabular}

Note. $\mathrm{Cl}$, confidence interval.

${ }^{\text {a } D a t a}$ on medical school affiliation, presence of a hospital epidemiologist, and full-time equivalents for infection preventionists were obtained from our survey data. The remaining data were obtained by linking respondents to the 2013 American Hospital Association database.

\section{CDI prevention, treatment, and testing practices}

The reported use of guideline-recommended ${ }^{18}$ CDI prevention practices, which have been shown to reduce CDI, was high (>90\%). Furthermore, CDI prevention was perceived as "important" or "very important" to hospital leadership in $89 \%$ of hospitals (Table 3). In contrast, use of innovative, "high-tech" methods for CDI prevention and availability of fecal microbiota transplant varied, with larger hospitals more likely to report their use. Across hospitals, methods of testing for CDI varied; approximately half of hospitals (56\%) used polymerase chain reaction (PCR) and $25 \%$ used a combination of testing methods. Larger hospitals were more likely to use PCR and less likely to use toxin or glutamate dehydrogenase antigen enzyme immunoassay (EIA) testing methods (Table 4).

\section{Diagnostic stewardship practices}

Hospitals commonly (91\%) reported rejecting formed stool that was submitted for CDI testing; however, the use of urine culture stewardship was uncommon (33\%). Both diagnostic stewardship practices increased with higher bed size (Table 4).

\section{Discussion}

In this large national survey of US hospitals, most hospitals had an antibiotic stewardship program and used evidence-based CDI prevention practices. Notably, the number of hospitals reporting antibiotic stewardship programs has nearly doubled in 4 years, ${ }^{8}$ coinciding with new US hospital accreditation standards. ${ }^{19}$ Nevertheless, few hospitals met accreditation standards for multidisciplinary teams and ID expertise was limited, particularly as hospital size decreased. Despite national interest in CDI prevention, practices varied across hospitals, with less use of novel CDI practices and diagnostic stewardship strategies, especially at small hospitals.

National society guidelines in the US have long recommended antibiotic stewardship as a key tool for CDI prevention. ${ }^{20}$ However, the use of antibiotic stewardship programs has been limited. ${ }^{8}$ Our survey revealed that antibiotic stewardship programs have become nearly universal following new national accreditation requirements. The Joint Commission is the top hospital accreditation body (accrediting $75 \%$ of hospitals in our survey), and this uptake in stewardship is likely related to the 2017 standard. Furthermore, although hospitals struggled to meet the specific 2017 Joint Commission recommendation for multidisciplinary antibiotic stewardship programs, nearly all hospitals had multidisciplinary stewardship teams, often including a pharmacist, a physician, and an infection preventionist.

Despite the critical role of pharmacists in antibiotic stewardship, only half of US hospitals reported having pharmacists with ID training. Specialized pharmacy training programs are a more recent development and training spots are in short supply, ${ }^{21}$ potentially limiting access to ID pharmacists, especially at smaller hospitals. Instead, clinical pharmacists without ID training often develop local expertise to improve antibiotic prescribing or obtaining additional training in stewardship through national organizations. Similarly, data suggest that antibiotic stewardship programs are best led by ID physicians with additional stewardship training. ${ }^{11,22}$ In our study, two-thirds of hospitals had ID physicians on their stewardship teams. Lack of ID-trained leaders at small hospitals may limit antibiotic stewardship: in 2015, only $31 \%$ of hospitals with $\leq 50$ beds met all CDC core elements. ${ }^{23}$ Although systematic changes to attract trainees to the field of ID and to antibiotic stewardship may help, this is a long-term solution. ${ }^{24,25}$ Other options to help distribute ID expertise across hospitals include access to expertise through quality collaboratives ${ }^{26}$ or "tele-stewardship" in which antibiotic use data are collected remotely and ID physicians are available via a stewardship "hotline." 27 The Infectious Diseases Society of America suggests telestewardship as a way to provide cost-effective subspecialty care to resource-limited populations. ${ }^{28,29}$ Unfortunately, many systems are prevented from using telestewardship due to medico-legal barriers and lack of financial reimbursement. ${ }^{30}$

Even with these strategies, the numbers of ID physicians specializing in antibiotic stewardship for all US acute-care hospitals, outpatient clinics, and long-term care facilities are insufficient. To account for this shortage, the CDC instead recommends that each critical access hospital ( $<25$ beds) have, at minimum, a pharmacist and physician on its stewardship team. ${ }^{13}$ In our survey, most small hospitals were able to meet this recommendation by having a non-ID physician, such as a hospitalist, on their stewardship team. Hospitalists can play a role in antibiotic stewardship because they prescribe most antibiotics for hospitalized patients, they can improve frontline provider buy-in, and they are often engaged in complementary quality improvement efforts. ${ }^{31-33}$ Similarly, the role of nurses in antibiotic and diagnostic stewardship is underappreciated but growing. ${ }^{34}$ A stewardship model that relies on pharmacy and physician generalists and nurses could apply not only to small hospitals, but to outpatient and long-term care settings where availability of ID experts are limited.

In addition to antibiotic stewardship, infection prevention strategies are critical in preventing CDI and are often 


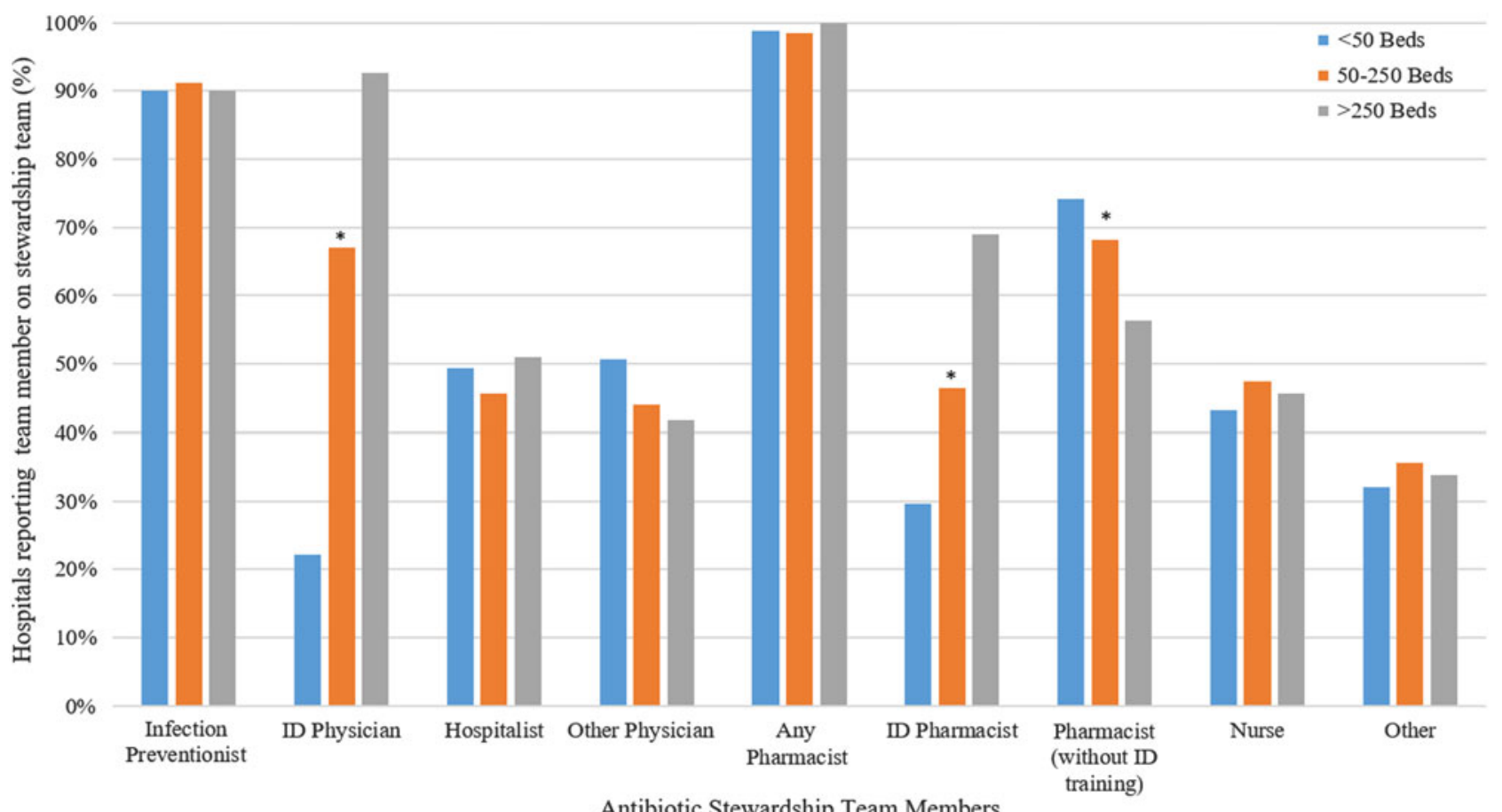

Fig. 1. Composition of antibiotic stewardship teams, by bed size ( $\mathrm{n}=493$ hospitals). ${ }^{\star}$ Indicates statistically significant odds ratio for every 10 -bed increase in bed size $(P<.05)$. Note. ID, infectious diseases.

Table 2. Antibiotic Stewardship Team Member Combinations by Bed Size ${ }^{\text {a }}$

\begin{tabular}{|c|c|c|c|c|c|c|}
\hline Variable & $\begin{array}{l}\text { All Hospitals } \\
(\mathrm{N}=493), \%\end{array}$ & $\begin{array}{l}<50 \text { Beds } \\
(\mathrm{N}=81), \%\end{array}$ & $\begin{array}{l}50-250 \text { Beds } \\
(\mathrm{N}=261), \%\end{array}$ & $\begin{array}{l}>250 \text { Beds } \\
(N=151), \%\end{array}$ & $\begin{array}{l}\text { Odds Ratio }(95 \% \mathrm{Cl}) \\
\text { per } 10 \text {-Bed Increase }\end{array}$ & $\begin{array}{c}P \\
\text { Value }\end{array}$ \\
\hline \multicolumn{7}{|l|}{ Antibiotic stewardship team combinations } \\
\hline ID physician and ID pharmacist & 43 & 11 & 36 & 66 & $1.06(1.04-1.08)$ & $<.0001$ \\
\hline ID physician or ID pharmacist & 78 & 41 & 77 & 95 & $1.12(1.08-1.16)$ & $<.0001$ \\
\hline Any Pharmacist & 99 & 99 & 99 & 100 & $1.14(1.05-1.24)$ & .001 \\
\hline $\begin{array}{l}\text { The Joint Commission recommendation: ID physician, } \\
\text { infection preventionist, pharmacist, practitioner }\end{array}$ & 41 & 11 & 39 & 56 & $1.02(1.01-1.04)$ & .004 \\
\hline $\begin{array}{l}\text { CDC recommendation for critical access hospitals: } \\
\text { pharmacist, physician }\end{array}$ & 95 & 89 & 94 & 98 & $1.05(1.01-1.09)$ & .02 \\
\hline
\end{tabular}

Note. ID, infectious diseases; CDC, Centers for Disease Control and Prevention. Includes hospitals $(\mathrm{N}=493)$ that reported having an antibiotic stewardship program.

asurvey responses are shown as weighted proportions with sampling weights based on the inverse probability of selection and response by bed size.

${ }^{b}$ Hospital bed size as reported by the American Hospital Association. $P<.05$ was considered significant.

c"Practitioner" is terminology used by The Joint Commission. For this analysis, ID physicians, hospitalists, and other physicians were included as practitioners.

multidisciplinary. Unlike stewardship, infection prevention has been a focus of US policies for decades; thus, it is not surprising that CDI prevention was considered important by hospital leadership and that evidence-based CDI prevention practices were common. The significance of variation in "high-tech" CDI prevention strategies is unclear because evidence for many of the practices is mixed and the cost is often quite high. Thus, small hospitals may be appropriately delaying purchasing expensive new technology until more evidence supports their use.

The lack of diagnostic stewardship strategies, especially at smaller hospitals, is concerning. For example, PCR techniques alone are only recommended to diagnose patients with a high pretest probability of
CDI; even then, a multistep algorithm including toxin is generally preferred. ${ }^{18}$ Thus, hospitals should implement diagnostic testing algorithms to improve CDI diagnostic accuracy. Ideally, such algorithms would include an assessment of symptoms and alternative causes to determine when testing is necessary. One high-yield method is automatically rejecting testing for CDI in patients with formed stools. ${ }^{14}$ Similarly, urine culture stewardship is key to reducing inappropriate antibiotic use for asymptomatic bacteriuria. ${ }^{35} \mathrm{Up}$ to $40 \%$ of hospitalized patients treated with antibiotics for presumed urinary tract infection have asymptomatic bacteriuria. ${ }^{36}$ Antibiotic use in this group increases adverse events and prolongs hospitalization without improving outcomes. ${ }^{36}$ 
Table 3. Guideline-Recommended Clostridioides difficile Infection Prevention Practices $^{a}$

\begin{tabular}{|c|c|}
\hline Variable & $\begin{array}{l}\text { Hospitals Reporting } \\
\text { Regular Use }{ }^{\mathrm{b}}(\mathrm{N}=528), \%\end{array}$ \\
\hline Contact precautions for duration of diarrhea & 99 \\
\hline $\begin{array}{l}\text { Private rooms or cohorting of patients } \\
\text { with } C D I\end{array}$ & 98 \\
\hline $\begin{array}{l}\text { Soap and water hand hygiene when exiting } \\
\text { CDI rooms }\end{array}$ & 92 \\
\hline $\begin{array}{l}\text { Thorough terminal cleaning and disinfecting } \\
\text { of hospital rooms and equipment used to } \\
\text { care for patients with CDI }\end{array}$ & 99 \\
\hline $\begin{array}{l}\text { Routine daily cleaning of high-touch surfaces } \\
\text { in CDI rooms }\end{array}$ & 90 \\
\hline $\begin{array}{l}\text { Established surveillance system for } \\
\text { monitoring CDI rates }\end{array}$ & 98 \\
\hline Report CDI rates to direct care providers & 90 \\
\hline $\begin{array}{l}\text { "Important" or "Very Important" to hospital } \\
\text { leadership to prevent CDIC }\end{array}$ & 89 \\
\hline \multicolumn{2}{|c|}{$\begin{array}{l}\text { Note. CDI, Clostridioides difficile infection. } \\
\text { aSurvey responses are shown as weighted proportions with sampling weights based on the } \\
\text { inverse probability of selection and response by bed size. } \\
\text { begular use is defined by a score of } 4 \text { or } 5 \text { on Likert scale. } \\
\text { 'Question used a Likert scale from } 1 \text { ("Not at all important") to } 5 \text { ("Very important"). }\end{array}$} \\
\hline
\end{tabular}

Our study has several limitations. First, we relied on selfreporting. Although infection preventionists are most likely to know their hospital's current practices related to CDI, their responses may not represent true practice. Second, while our sampling strategy was designed to obtain a nationally representative sample, it is possible that participating hospitals differed from nonparticipating hospitals. For example, hospitals with less developed stewardship and infection prevention teams may have been less likely to respond. Third, because we did not collect data on availability of ID specialists, we were unable to determine whether lack of ID involvement in stewardship at small hospitals reflected limited access or limited interest by available ID specialists. Finally, due to the inherent difficulties with survey methodology we were unable to assess the implementation of CDI and diagnostic stewardship strategies.

Herein, we have provided a snapshot of antibiotic stewardship program team composition, CDI strategies, and diagnostic stewardship in US hospitals in the period immediately following the 2017 Joint Commission standard for antibiotic stewardship. Although nearly all hospitals now have an antibiotic stewardship program, team compositions differ by hospital size, and most hospitals do not meet ideal recommendations for multidisciplinary teams. Specifically, smaller hospitals appear to have limited ID expertise on their stewardship teams and to struggle with deploying diagnostic stewardship strategies. In addition to

Table 4. Clostridioides difficile Infection Related-Practices and Diagnostic Stewardship Strategies by Bed Size ${ }^{\mathrm{a}}$

\begin{tabular}{|c|c|c|c|c|c|c|}
\hline Variable & $\begin{array}{c}\text { Hospitals } \\
\text { Reporting Regular } \\
\text { Use } \mathrm{b}^{\mathrm{b}}(\mathrm{N}=528), \%\end{array}$ & $\begin{array}{l}<50 \text { Beds } \\
(N=98), \%\end{array}$ & $\begin{array}{l}50-250 \text { Beds } \\
(\mathrm{N}=277), \%\end{array}$ & $\begin{array}{l}>250 \text { Beds } \\
(\mathrm{N}=153), \%\end{array}$ & $\begin{array}{c}\text { Odds Ratio } \\
(95 \% \mathrm{Cl}) \text { per } \\
10 \text {-Bed Increase }\end{array}$ & $\begin{array}{c}P \\
\text { Value }^{\mathrm{c}}\end{array}$ \\
\hline \multicolumn{7}{|l|}{ "High-tech" CDI Prevention Practices } \\
\hline $\begin{array}{l}\text { Use supplemental no-touch disinfection devices for CDI rooms } \\
\text { (eg, UV germicidal irradiation, hydrogen peroxide vapor) }\end{array}$ & 29 & 10 & 26 & 44 & $1.035(1.024-1.046)$ & $<.0001$ \\
\hline $\begin{array}{l}\text { Use real-time methods to assess thoroughness of cleaning/ } \\
\text { disinfection of surfaces in CDI rooms (eg, fluorescent marker, ATP) }\end{array}$ & 72 & 52 & 72 & 83 & $1.035(1.018-1.052)$ & $<.0001$ \\
\hline Offer fecal microbiota transplant for patients with recurrent CDI & 32 & 5 & 29 & 50 & $1.041(1.027-1.054)$ & $<.0001$ \\
\hline \multicolumn{7}{|l|}{ C. difficile testing strategies } \\
\hline \multicolumn{7}{|l|}{ Primary test used for $C$. difficile } \\
\hline Antigen EIA & 3 & 7 & 3 & 0 & $.911(.856-.970)$ & .004 \\
\hline Some combination of above & 25 & 23 & 26 & 25 & $.999(.989-1.009)$ & .83 \\
\hline $\begin{array}{l}\text { Have a written policy to routinely test for CDI when patients } \\
\text { have diarrhea while on or within several months of taking } \\
\text { antibiotics }\end{array}$ & 35 & 39 & 36 & 30 & $.987(.977-.998)$ & .02 \\
\hline Clinicians educated as to when to order $C$. difficile testing & 88 & 86 & 88 & 90 & $1.004(.984-1.024)$ & .73 \\
\hline \multicolumn{7}{|l|}{ Diagnostic stewardship strategies } \\
\hline $\begin{array}{l}\text { Laboratory rejects formed stools submitted for } C \text {. difficile } \\
\text { testing }\end{array}$ & 91 & 77 & 93 & 95 & $1.057(1.022-1.093)$ & .002 \\
\hline Urine culture stewardship initiative & 33 & 27 & 32 & 36 & $1.011(1.000-1.022)$ & .04 \\
\hline
\end{tabular}

Note. ATP, adenosine triphosphate; CDI, Clostridioides difficile infection; C. difficile, Clostridioides difficile; EIA, enzyme immunoassay; PCR, polymerase chain reaction; UV, ultraviolet. aSurvey responses are shown as weighted proportions with sampling weights based on the inverse probability of selection and response by bed size.

${ }^{b}$ Regular use is defined by a score of 4 or 5 on Likert scale.

'Hospital bed size as reported by the American Hospital Association. $P<.05$ was considered significant. 
implementing diagnostic stewardship, preventing CDI at small hospitals may be enhanced by emphasizing the role of generalists, such as clinical pharmacists, nurses, and hospitalists, in antibiotic stewardship.

Acknowledgments. The findings and conclusions in this manuscript are those of the authors and do not necessarily represent the official position of the Department of Veterans Affairs.

Financial support. This work was supported by the Blue Cross Blue Shield of Michigan Foundation (grant no. 2413.II) and a US Department of Veterans' Affairs (VA) National Center for Patient Safety funded Patient Safety Center of Inquiry. Dr. Krein was also supported by a VA Health Services Research and Development Service Research Career Scientist award (grant no. RCS 11-222).

Conflicts of interest. Dr. Flanders has received royalties from Wiley Publishing and expert witness testimony and grant support from Blue Cross Blue Shield of Michigan and the Agency for Healthcare Research and Quality.

\section{References}

1. Davies KA, Longshaw CM, Davis GL, et al. Underdiagnosis of Clostridium difficile across Europe: the European, multicentre, prospective, biannual, point-prevalence study of Clostridium difficile infection in hospitalised patients with diarrhoea (EUCLID). Lancet Infect Dis 2014;14:1208-1219.

2. Lessa FC, Mu Y, Bamberg WM, et al. Burden of Clostridium difficile infection in the United States. N Engl J Med 2015;372:825-834.

3. Centers for Disease Control and Prevention. Vital signs: preventing Clostridium difficile infections. Morbid Mortal Wkly Rept 2012;61:157.

4. Magill SS, O'Leary E, Janelle SJ, et al. Changes in prevalence of health careassociated infections in US Hospitals. N Engl J Med 2018;379:1732-1744.

5. Dubberke ER, Rohde JM, Saint S, et al. Quantitative results of a national intervention to prevent Clostridioides difficile infection: a pre-post observational study. Ann Intern Med 2019;171:S52-S58.

6. Gerding DN, Muto CA, Owens RC Jr. Measures to control and prevent Clostridium difficile infection. Clin Infect Dis 2008;46 suppl 1:S43-S49.

7. Wilcox MH, Shetty N, Fawley WN, et al. Changing epidemiology of Clostridium difficile infection following the introduction of a national ribotyping-based surveillance scheme in England. Clin Infect Dis 2012;55: 1056-1063.

8. Saint S, Fowler KE, Krein SL, et al. Clostridium difficile infection in the United States: a national study assessing preventive practices used and perceptions of practice evidence. Infect Control Hosp Epidemiol 2015;36:969-971.

9. Pollack LA, van Santen KL, Weiner LM, Dudeck MA, Edwards JR, Srinivasan A. Antibiotic stewardship programs in US acute-care hospitals: findings from the 2014 National Healthcare Safety Network Annual Hospital Survey. Rev Infect Dis 2016;63:443-449.

10. Dingle KE, Didelot X, Quan TP, et al. Effects of control interventions on Clostridium difficile infection in England: an observational study. Lancet Infect Dis 2017;17:411-421.

11. Barlam TF, Cosgrove SE, Abbo LM, et al. Implementing an antibiotic stewardship program: guidelines by the Infectious Diseases Society of America and the Society for Healthcare Epidemiology of America. Clin Infect Dis 2016;62:e51-e77.

12. Chandrasekar P, Havlichek D, Johnson LB. Infectious diseases subspecialty: declining demand challenges and opportunities. Clin Infect Dis 2014;59: 1593-1598.

13. Implementation of antibiotic stewardship core elements at small and critical access hospitals. Centers for Disease Control and Prevention website. https://www.cdc.gov/antibiotic-use/healthcare/implementation/coreelements-small-critical.html. Published 2015. Accessed July 27, 2018.

14. Morgan DJ, Malani P, Diekema DJ. Diagnostic stewardship—leveraging the laboratory to improve antimicrobial use. JAMA 2017;318:607-608.

15. Krein SL, Kowalski CP, Hofer TP, Saint S. Preventing hospital-acquired infections: a national survey of practices reported by US hospitals in 2005 and 2009. J Gen Intern Med 2012;27:773-779.
16. Saint S, Kowalski CP, Kaufman SR, et al. Preventing hospital-acquired urinary tract infection in the United States: a national study. Clin Infect Dis 2008;46:243-250.

17. Krein SL, Hofer TP, Kowalski CP, et al. Use of central venous catheterrelated bloodstream infection prevention practices by US hospitals. Mayo Clin Proc 2007;82:672-678.

18. McDonald LC, Gerding DN, Johnson S, et al. Clinical practice guidelines for Clostridium difficile infection in adults and children: 2017 update by the Infectious Diseases Society of America (IDSA) and Society for Healthcare Epidemiology of America (SHEA). Clin Infect Dis 2018;66:e1-e48.

19. Joint Commission. Approved: new antimicrobial stewardship standard. Jt Comm Perspect 2016;36:1-3.

20. Cohen SH, Gerding DN, Johnson S, et al. Clinical practice guidelines for Clostridium difficile infection in adults: 2010 update by the Society for Healthcare Epidemiology of America (SHEA) and the Infectious Diseases Society of America (IDSA). Infect Control Hosp Epidemiol 2010;31:431-455.

21. Gauthier TP, Worley M, Laboy V, et al. Clinical infectious diseases pharmacists in the United States: a problem of both supply and demand. Clin Infect Dis 2015;60:826-827.

22. Ostrowsky B, Banerjee R, Bonomo RA, et al. Infectious diseases physicians: leading the way in antimicrobial stewardship. Clin Infect Dis 2018;66:995-1003.

23. O'Leary EN, van Santen KL, Webb AK, Pollock DA, Edwards JR, Srinivasan A. Uptake of antibiotic stewardship programs in US acute care hospitals: findings from the 2015 National Healthcare Safety Network annual hospital survey. Clin Infect Dis 2017;65:1748-1750.

24. Luther VP, Shnekendorf R, Abbo LM, et al. Antimicrobial stewardship training for infectious diseases fellows: program directors identify a curriculum need. Clin Infect Dis 2018;67:1285-1287.

25. Walensky RP, Del Rio C, Armstrong WS. Charting the future of infectious disease: anticipating and addressing the supply and demand mismatch. Clin Infect Dis 2017;64:1299-1301.

26. Vaughn VM, Gandhi T, Conlon A, Chopra V, Malani AN, Flanders SA. The association of antibiotic stewardship with fluoroquinolone prescribing in michigan hospitals: a multi-hospital cohort study. Clin Infect Dis 2019;69: 1269-1277.

27. Stenehjem E, Hersh AL, Buckel WR, et al. Impact of implementing antibiotic stewardship programs in 15 small hospitals: a cluster-randomized intervention. Clin Infect Dis 2018;67:525-532.

28. Young JD, Abdel-Massih R, Herchline T, et al. Infectious Diseases Society of America position statement on telehealth and telemedicine as applied to the practice of infectious diseases. Clin Infect Dis 2019;68:1437-1443.

29. Siddiqui J, Herchline T, Kahlon S, et al. Infectious Diseases Society of America position statement on telehealth and telemedicine as applied to the practice of infectious diseases. Clin Infect Dis 2017;64:237-242.

30. Bishop J, Kong DC, Schulz TR, Thursky KA, Buising KL. Meeting the challenge for effective antimicrobial stewardship programs in regional, rural and remote hospitals - what can we learn from the published literature? Rural Remote Health 2018;18:4442.

31. Vaughn VM, Flanders SA. Web exclusives: annals for hospitalists inpatient notes-mindfulness and antibiotic appropriateness-how point-of-care stewardship begins with hospitalists. Ann Intern Med 2016;165:HO2-HO3.

32. Srinivasan A. Engaging hospitalists in antimicrobial stewardship: the $\mathrm{CDC}$ perspective. J Hosp Med 2011;6 suppl 1:S31-S33.

33. Mack MR, Rohde JM, Jacobsen D, et al. Engaging hospitalists in antimicrobial stewardship: lessons from a multihospital collaborative. J Hosp Med 2016;11:576-580.

34. Carter EJ, Greendyke WG, Furuya EY, et al. Exploring the nurses' role in antibiotic stewardship: a multisite qualitative study of nurses and infection preventionists. Am J Infect Control 2018;46:492-497.

35. Brown KA, Daneman N, Schwartz KL, et al. The urine culturing cascade: variation in nursing home urine culturing and association with antibiotic use and C. difficile infection. Clin Infect Dis 2019. doi: 10.1093/cid/ciz482.

36. Petty LA, Vaughn VM, Flanders SA, et al. Risk factors and outcomes associated with treatment of asymptomatic bacteriuria in hospitalized patients. JAMA Intern Med 2019. doi: 10.1001/jamainternmed.2019.2871. 